\title{
Random behavior in regular spike times: a phase function to find periodicity in spike time sequences, and its application to globus pallidus neurons
}

\author{
Ramana Dodla*, Charles J Wilson \\ From Nineteenth Annual Computational Neuroscience Meeting: CNS*2010 \\ San Antonio, TX, USA. 24-30 July 2010
}

Real spike time sequences can exhibit considerable variability. Conventional correlation methods $[1,2]$ that require in general long time duration sequences cannot be reliably used to discover frequency components or time constants that might exist at shorter time scales. Recently we introduced a phasefunction method [3] to characterize much shorter duration spike time data, which can show periodicity and time constants present in fewer number of spike times than needed by correlation methods. We use an autophase function to systematically explore the temporal frequencies in spike time sequences recorded from rat globus pallidus neurons of basal ganglia in slices.

Globus pallidus neurons spike spontaneously. The spontaneity can produce rhythmic oscillations over hours of in vitro recordings. However, the spike times are known to have considerable variability among spike times $[4,5]$. The change in variability can be on the order of seconds. The resultant interspike interval histograms defy conventional classification into gamma distributions, and instead follow approximately log-normal distributions. Application of autophase function method to these spike times reveals strong periodicity at short time scales. Thus it is puzzling that a random distribution can emerge from such strong oscillations. We investigate the changes in periodicity in time in globus pallidus neurons, and the effect of rate on the disruption of their frequency.

\section{Acknowledgements}

Supported by NIH / NINDS NS47085. Computational support by Texas Advanced Computing Center, University of Texas at Austin, and

\footnotetext{
* Correspondence: ramana.dodla@utsa.edu

Department of Biology, University of Texas at San Antonio, TX 78249, USA
}

Computational Biology Initiative at University of Texas Health Science Center at San Antonio/University of Texas at San Antonio.

Published: 20 July 2010

\section{References}

1. Moore GP, Perkel DH, Segundo JP: Statistical analysis and functional interpretation of neuronal spike data. Annu Rev Physiol 1966, 28:493-522.

2. Brown EN, Kass RE, Mitra PP: Multiple neural spike train data analysis: state-of-the-art and the future challenges. Nature Neurosci 2004, 7:456-461

3. Dodla R, Wilson CJ: A phase function to quantify serial dependence between discrete samples. Biophys J 2010, 98:L5-L7.

4. Stanford IM: Independent neuronal oscillators of the rat globus pallidus. J Neurophysiol 2003, 89:1713-1717.

5. Deister CA, Chan CS, Surmeier DJ, Wilson CJ: Calcium-activated SK channel voltage-gated ion channels to determine the precision of firing in globus pallidus neurons. J Neurosci 2009, 29:8452-8461.

doi:10.1186/1471-2202-11-S1-P8

Cite this article as: Dodla and Wilson: Random behavior in regular spike times: a phase function to find periodicity in spike time sequences, and its application to globus pallidus neurons. BMC Neuroscience 2010 11(Suppl 1):P8.

\section{Submit your next manuscript to BioMed Central and take full advantage of: \\ - Convenient online submission \\ - Thorough peer review \\ - No space constraints or color figure charges \\ - Immediate publication on acceptance \\ - Inclusion in PubMed, CAS, Scopus and Google Scholar \\ - Research which is freely available for redistribution

